\title{
The sequential twinning-transformation induced plasticity effects in a thermomechanically processed high Mn austenitic steel
}

\author{
H. Eskandari Sabzi ${ }^{a}$, A. Zarei Hanzaki ${ }^{a, 1}$, H.R. Abedi ${ }^{a}$, A. Mateo ${ }^{b}$ and J.J. Roa ${ }^{b}$ \\ a- Hot Deformation \& Thermomechanical Processing of High Performance Engineering Materials Lab, \\ School of Metallurgy and Materials Engineering, College of Engineering, University of Tehran, Tehran, \\ Iran \\ b-CIEFMA-Department of Materials Science and Metallurgy, Barcelona East School of Engineering \\ (EEBE) of Barcelona, Universitat Politècnica de Catalunya, 08019 Barcelona, Spain
}

\begin{abstract}
Different initial microstructures with various bimodal grain size distributions (BGSD) were produced in a high $\mathrm{Mn}$ austenitic steel through applying a predetermined set of thermomechanical processing cycles. The corresponding room temperature mechanical properties and the related strain hardening behaviors were assessed using tensile testing method. The results indicated that in the microstructure with high grain size bimodality, the length and amplitude of rapid hardening region was well higher than the others. This was attributed to its higher capability to $\alpha^{\prime}$-martensite formation. In addition, the threshold strain to initiate martensitic transformation was shifted to the lower one in the microstructure with higher bimodal grain size distribution. The latter was related to the lower arisen back stresses in the interior regions of the coarser grains. Furthermore, different transformation paths were identified as the BGSD changed. The austenite could directly transform to $\alpha^{\prime}$-martensite $\left(\gamma \rightarrow \alpha^{\prime}\right)$ in the microstructure with lower BGSD; in this case the $\alpha^{\prime}$-martensite mainly appeared at the intersections of deformation twins. In contrast, in microstructures with higher BGSD, the nucleation occurred at the intersections of $\varepsilon$-martensite platelets. The co-existence of these transformation paths provided an extended transformation induced plasticity effect ending to a higher elongation to fracture in the course of deformation. In order to summarize the contribution of various strain hardening mechanisms, a deformation map was also constructed. Accordingly, the enhanced ductility/strength properties were attributed to the sequential operation of extended transformation induced plasticity and twinning induced plasticity effects.
\end{abstract}

Keywords: Transformation-twinning induced plasticity steel; Strain hardening rate; Deformation twins; Martensitic transformation; $\alpha^{\prime}$-martensite

\footnotetext{
1 * Corresponding author, e-mail: zareih@ut.ac.ir Tel: 98.21.82084116, Fax: 98.21.88006076
} 


\section{Introduction}

The twinning and transformation induced plasticity (TWIP and TRIP) effects are thought to be potentially capable of rendering exceptional strain hardening to the austenitic steels under plastic deformation. Both TRIP and TWIP effects may simultaneously occur, where the stacking fault energy lays in the range of $18-22 \mathrm{~mJ} / \mathrm{m}^{2}[1-3]$. In this respect, an extra hardening capability would be achieved and an intensified rapid hardening region would be expanded over a wide range of imposed strain. The deformation-induced twinning would increase the ductility through instantaneous crystal rotation and would also increase the strength by bringing about the fresh obstacles to dislocation glide, as a so-called dynamic Hall-Petch effect [4]. The epsilon or alpha prime martensites also act as efficient barrier to the dislocation movement and increase the rate of strain hardening. In addition, the imposed strain may be additionally accommodated through the occurrence of extended TRIPing; where the metastable austenitic matrix transforms to martensite in two stage via an intermediate state; first to the $\varepsilon$-martensite exhibiting an $\mathrm{HCP}$ lattice structure and then into the BCC $\alpha^{\prime}$-martensite [5,6]. It was found that the kinetics of martensitic phase transformation were enhanced if the metastable austenite would transform from $\varepsilon$ - into $\alpha^{\prime}$-martensite [7]. Furthermore, deformation twinning may substantially interact with $\varepsilon$ or $\alpha^{\prime}$ martensite platelets [8], and may also significantly reduce the mean free path of dislocations movements.

The grain size is considered as the main microstructural parameter which may significantly influence the sequence and extent of the aforementioned mechanisms. It is generally accepted that the grain refinement may suppress the martensitic transformation or deformation twinning [9]. However, Ueji et al. reported the occurrence of deformation twinning even in grain sizes down to $2 \mu \mathrm{m}$, but the suppression could be stimulated by finer grain sizes. 
Up to date, numerous investigations have been performed on different class of austenitic steels in metastable state in order to achieve a deeper understanding and knowledge of the corresponding microstructural evolutions and their influences on the related mechanical properties $[10,11]$. However, appreciating all the previous attempts, the resultant peculiar strain hardening mechanisms are still not fully understood, and the extent and the sequence of various proposed mechanisms yet being a matter of debate. In order to better clarify and shade more light on the nature, sequence and contribution of TRIP and TWIP effects in the observed strain hardening behavior, a high $\mathrm{Mn}$ austenitic steel was microstructurally and mechanically investigated under tensile testing technique. The various initial microstructures with respect of grain size and its distribution were generated by applying contemplated thermomechanical processing cycles. The deliberated examinations of two different initial microstructures holding different grain sizes could explain the deformation band formation and assist elucidating the strain hardening mechanisms of the austenite. The present study is expected to provide an open window toward the application of a new generation of light weight advanced high strength automotive steels.

\section{Experimental procedure}

The investigated steel was received in as electro-slag remelted condition possessing the chemical composition of Fe-21Mn-1.6Al-2.5Si-0.1C (wt\%). The stacking fault energy of experimental material, which lies in the range of $18-22 \mathrm{~mJ} / \mathrm{m}^{2}$ at $25^{\circ} \mathrm{C}$, was calculated through Olsen and Cohen model [7]. This means that the experimental material could enjoy tolerating both the TWIP and TRIP effects simultaneously [12]. In order to generate two different initial microstructures (in particular different grain size and distribution), the ingots were hot rolled 
down to $30 \%$ thickness reduction in 1 pass at two different temperatures of $1200^{\circ} \mathrm{C}$ and $1000^{\circ} \mathrm{C}$ followed by air cooling. The effects of rolling temperature on the grain size of the present steel has been recently studied [13]. The corresponding microstructures are given in Fig. 1a and $\mathbf{b}$. The mean grain sizes of the corresponding microstructures were reported as $\sim 16 \mu \mathrm{m}$ and $\sim 22 \mu \mathrm{m}$, respectively. Interestingly, the differences in mean grain sizes were not considerable, but the grain size distributions were significantly different. To be more precise, the bimodal grain size distribution (BGSD) was quantified and represented in Table 1. Here, the aspect ratio is defined as the ratio of the major to minor axis of the ellipse enclosing each grain. At least 15 grains were considered in each region of the developed microstructures. The average aspect ratio of the fine regions of the both microstructures are 2.1 and 1.6, however the average ratio of the coarse region are 4.8 and 3.5, respectively. These measurements revealed that the developed microstructures were heterogeneous. The mean grain size of the low bimodal (the specimen rolled at $1000^{\circ} \mathrm{C}$ ) and high bimodal (the specimen rolled at $1200^{\circ} \mathrm{C}$ ) structures are almost the same, but the mean grain size of the coarse region of the high bimodal structure was further larger than that of low bimodal structure $(55 \mu \mathrm{m}$ and $23 \mu \mathrm{m}$, respectively). The initial macrotexture of the specimens after hot rolling and prior to tensile testing was also measured by XRD and shown in Fig. 1c, $\mathbf{d}$ and $\mathbf{e}$. As is clearly observed, there is no preferred initial texture after hot rolling at different temperatures. Therefore, the probably effects of texture on the different deformation mechanisms can be neglected. The tensile testing method was utilized to study the mechanical behavior of the processed materials. All the tensile tests were performed using a Santam-20KN universal testing machine holding a load accuracy of $1 \mathrm{~N}$ under the strain rate of $10^{-3} \mathrm{~s}^{-1}$ at room temperature. In addition to conducting at least three tensile tests up to fracture, some interrupted tests were also implemented by straining up to various logarithmic strains in 
order to follow the involved deformation mechanisms. The microstructures of these specimens after deformation were examined by electron back-scattered diffraction (EBSD) microscopy. The EBSD scans were performed by a JSM-7001F field emission scanning electron microscope (FESEM) equipped with Channel 5 system (HKL Technology), operating at $20 \mathrm{kV}$ with specimens tilted $70^{\circ}$. To determine the martensite phase fractions, to analyze the evolved microstructure and measuring macro-texture of the specimens, the X-ray diffraction (XRD) trials were carried out using a Philips X'Pert PRO apparatus with a rotating copper anode $(\mathrm{Cu} \mathrm{Ka1)}$ radiation and wave length of $\lambda=1.5406 \dot{A}$. The quantitative phase analysis method has been explained elsewhere by Murdock et al. [23].

\section{Results and discussions}

The room temperature tensile flow curves of the thermomechanically processed materials are presented in Fig. 2, to assess the capability of experimental steel in experiencing TWIP and/or TRIP effects. For further clarification, the corresponding strain hardening behaviors are also superimposed. The plastic deformation behavior may be classified into the five stages according to the corresponding inflection points in the strain hardening curves. Stage A is attributed to the elastic deformation. By starting the plastic region, the strain hardening rate drops rapidly during initial deformation stage (Stage B), and then reaches to a relatively steady state region (Stage C). Interestingly, a rapid hardening region (Stage D) can be clearly recognized for the specimen rolled at $1200^{\circ} \mathrm{C}$, whereas the rate of strain hardening remained stable in the specimen rolled at $1000^{\circ} \mathrm{C}$. Finally, both of the curves quickly drop down to fracture in Stage E. To rationalize the aforementioned inflections in the rate of work hardening, the contribution of martensitic transformation should be identified through monitoring the formation of epsilon and 
alpha prime martensite at various imposed strains. In this regard, the micro-constituent phases volume fractions were calculated through X-ray diffraction method. The obtained results are presented in Fig. 3. As is seen, in comparison with the fully austenitic microstructure, the amounts of $\varepsilon^{-}$ and $\alpha^{\prime}$-martensite in the deformed specimens are substantial; this would suggest the occurrence of strain induced $\gamma \rightarrow \alpha^{\prime}$ and/or $\gamma \rightarrow \varepsilon$ transformations during straining. The variation of $\alpha^{\prime}-$ and $\varepsilon^{-}$ martensite volume fractions vs. logarithmic strain is furnished by rate of strain hardening in Fig. 4. As is seen, at the first hardening stage of plastic deformation (i.e. Stage B, logarithmic strain $<0.15)$ the formation of $\varepsilon$-martensite is predominant where the volume fraction of the austenite is decreased even down to $60 \%$. Comparatively, the contribution of $\alpha^{\prime}$-martensite is insignificant. At the Stage $\mathrm{C}$ of hardening behavior, two various trends can be recognized. In the specimen which was processed at $1000^{\circ} \mathrm{C}$ (low bimodality factor), the $\gamma \rightarrow \varepsilon$ phase transformation continues (Fig. 3a), whereas, the transformation appears to be somehow suppressed in the case of the specimen rolled at $1200^{\circ} \mathrm{C}$ (high bimodality factor) (Fig. 3b). In the Stage D, the volume fraction of $\alpha^{\prime}$-martensite is rapidly increased in both specimens. Finally, in Stage E, the volume fraction of $\varepsilon$-martensite decreased by increasing the deformation, but that of $\alpha^{\prime}$-martensite follows an opposite trend. Considering the relatively low stacking fault energy of the austenite $\left(\sim 19 \mathrm{~mJ} / \mathrm{m}^{2}\right)$ in the present experimental alloy, it is expected that the planar dislocation substructures such as stacking faults and pile-ups being created during initial straining. The $\varepsilon$-martensite formation is believed initiating by the overlapped stacking faults on the close-packed (111) planes. The latter has been thoroughly demonstrated in previous researches $[14,15]$. Stage B of the strain hardening behavior is therefore associated with the glide of partial dislocations and $\varepsilon$-martensite formation in both structures with different grain size distributions. The $\varepsilon$-martensite formation continues to be dominated in the Stage $\mathrm{C}$ in the case of 
low $\mathrm{BF}$ microstructure. In contrast, the Stage $\mathrm{C}$ is dominated by the formation of $\alpha^{\prime}$-martensite in high $\mathrm{BF}$ microstructure, where the rate of decrease in the strain hardening rate is substantially reduced. By further increase in imposed tensile strain, the $\alpha^{\prime}$-martensite volume fraction is continuously increased. The transition from Stage C to D occurs at a critical strain by which the maximum $\varepsilon$ fraction is achieved and the contribution of $\alpha^{\prime}$ is considerable. The main point is the fact that the length and amplitude of rapid hardening region is well higher in the case of microstructure holding high bimodality factor (BF). The latter may be attributed to the capability of the microstructure for $\alpha^{\prime}$-martensite formation. Eventually, the rate of martensite formation and the rate of strain hardening is being decreased up to fracture.

As was observed, the X-ray results clearly verify the occurrence of transformation induced plasticity effect during room temperature deformation of the experimental materials. However, it is expected that the occurrence of twinning contributes in strain hardening at various strain levels too. The latter is also grain size dependent and would be precisely addressed in the following sections. The phase maps of the microstructures which have been elongated up to the logarithmic strain of 0.1 and 0.27 are depicted in Fig. 5. These specimens were machined from the material which had been previously thermomechanically processed at $1000^{\circ} \mathrm{C}$. The blue, green and red areas imply to the presence of austenite, $\varepsilon$-martensite and $\alpha^{\prime}$-martensite, respectively. The corresponding twin boundary maps are also given. The main point, which should be followed in the developed microstructures, is the appreciable contribution of deformation twinning at various stages of strain hardening (Fig. 5b and d). In addition, the deformation induced $\alpha^{\prime}$-martensite platelets are mainly observed at the intersections of deformation twins (Fig. 5c and d). It is worth mentioning that the critical shear stress for twinning is believed to be lower than that of martensitic transformation in smaller grain size 
structures; in addition, grain refinement is generally considered to suppress the mechanical twinning [16,17]. However, the grain refinement to micrometer ranges may not suppress the deformation twinning, though the grain size reduction to lower than $3 \mu \mathrm{m}$ would be influential $[18,19]$. The high bimodal grain size distribution microstructures (e.g., the material hot rolled at $1200^{\circ} \mathrm{C}$ ) was also tensile deformed at ambient temperature up to the strain $0.1,0.35$ and 0.45 , and the corresponding microstructures are shown in Fig. 6. The fraction of $\varepsilon$-martensite is obviously higher, and the contribution of twinning appears to be considerably lower at various imposed strains in comparison to the lower BF material (Fig. 6a and b). Furthermore, the $\alpha^{\prime}-$ martensite formation has been occurred over a wide range of strain. This is attributed to the fact that the martensitic transformation mode may changes from multi-variant to single-variant transformation due to the grain size refinement down to $10 \mu \mathrm{m}$ (similar to the present mean grain size). This was thoroughly addressed in previous researches $[9,20]$. As was noted, the mean grain size of the coarse region in low BF microstructure is much lower than that of its counterparts in the high BF microstructure. Therefore, the occurrence of martensitic transformation in the extended form is expected in higher bimodal grain size distribution structure, and the critical strain required for transformation may shift to the lower imposed strains. In fact, the coarser grain regions accommodate the strain at early stages of deformation due to their lower strength compared to the finer grain size regions. Therefore, the coarse grains in higher BF structure, which its deform may be assisted by martensitic transformation, contribute at the early stages of deformation and twinning which occur in the finer grain sizes would be activated at higher imposed strains. In the microstructure holding lower bimodality factor, the formation of stacking faults can be retarded by the back-stresses from dislocation pile up at the grain boundaries thereby the dissociated dislocations could recombine, enabling their cross-slip. In contrast, at the 
larger grain size, the stacking faults are wider and would experience lower back-stresses from grain boundaries. Accordingly, the stress, which is necessary to form alpha prime martensite nuclei, can be smaller in the coarse-grained states.

Both investigated microstructures are capable of $\alpha^{\prime}$-martensite formation, however the observed transformation path $(\gamma \rightarrow \varepsilon \rightarrow \alpha)$ is completely different (in the case of structure with lower BF the transformation sequence is as $\gamma \rightarrow \alpha^{\prime}$ ). According to the Schumann et al. [21], the critical Mn content for the transition of transformation path from $\gamma \rightarrow \alpha^{\prime}$ to $\gamma \rightarrow \varepsilon \rightarrow \alpha^{\prime}$ was reported to be around $10 \mathrm{wt} \%$. In the present case, despite the high Mn content the austenite may directly transform to $\alpha^{\prime}$-martensite in the microstructure with lower BF. This further highlights the significant effects of austenite grain size and its size distribution on the contribution of deformation twinning and martensitic transformation in the present case. Since in the former path, in which the $\alpha^{\prime}$-martensite nucleates at the intersections of $\varepsilon$-martensite platelets, the transformation to final product is being extended, a higher elongation to fracture value would be expected.

Fig. 7 shows a schematic description of the dominant deformation mechanisms in the present investigated steel. After elastic deformation, stacking fault and $\varepsilon$-martensite formation are activated at the first stage of strain hardening behavior in both thermo-mechanical processing conditions. In addition, the twinning frequency is considerable in the microstructure with lower $\mathrm{BF}$ after tensile straining up to the first hardening stage $(\varepsilon<0.15)$. By higher imposed strains (Stage C) the twinning was still characterized as dominant mechanism for the thermomechanically treated at $1000^{\circ} \mathrm{C}$. In this stage, the transformation from austenite to $\alpha^{\prime}-$ martensite through the intermediate $\varepsilon$ phase can be detected for the material which was processed at $1200^{\circ} \mathrm{C}$. In the rapid hardening stage (Stage D), which is seen in high BF structure, $\alpha^{\prime}-$ 
martensite formation occurs in both structures with low and high BF. However, the transformation path is completely different. The hot rolled material at $1200^{\circ} \mathrm{C}$ keeps the same path as the previous stage, but in the processed material at $1000^{\circ} \mathrm{C}$ the $\alpha^{\prime}$-martensite is formed at twin boundaries and their intersections. Subsequently, the twinning and martensitic transformation continues up to fracture but with slower kinetics. It is worth noting that the deformation twinning may act as obstacles against dislocation movement thereby increasing the rate of work hardening, but this would be masked by the higher contribution of $\alpha^{\prime}$-martensite formation in strain hardening. This is completely in agreement with the previous report by Qin et al. [22]. However, in the present case, the twin boundaries may effectively act as nucleation sites for martensitic transformation in lower BF structures. As a final point, owning to the superior capability of higher BF structures to transformation induced plasticity effects, the threshold strain for rapid hardening stage shifts to lower logarithmic strains thereby resulting in the highest strength and ductility values.

\section{Conclusions}

The room temperature strain hardening behaviors of an austenitic high Mn TRIP-TWIP steel holding two various initial microstructures (different grain size distributions) were thoroughly investigated. The results indicated that the grain size distribution bimodality might significantly influence the sequence and the extent of TRIP and TWIP effects during tensile deformation and consequently the strength/ductility values. The initial stage of plastic strain hardening was associated with the glide of partial dislocations and $\varepsilon$-martensite formation in both grain size bimodalities. The $\varepsilon$-martensite formation continued to be dominant up to the intermediate stage in the microstructure with lower bimodality factor. In contrast, the $\alpha^{\prime}-$ martensite formation was the governing plasticity micro-mechanism in the microstructure with 
higher bimodality factor; in this case the rate of decrease in the strain hardening rate was substantially reduced. Interestingly, the rapid hardening region could be clearly recognized in the specimen with high bimodality factor. However, the strain hardening rate was being constant in the case of lower bimodality factor. The latter was attributed to the capability of the microstructure for $\alpha^{\prime}$-martensite formation. The martensitic transformation in the microstructure holding higher bimodality followed an extended form $(\gamma \rightarrow \varepsilon \rightarrow \alpha)$ and was completely different from ones which was observed in the case of lower bimodality one $\left(\gamma \rightarrow \alpha^{\prime}\right)$. The deformation twinning also contributed to the strain hardening behavior, but its effects were somehow masked by the $\alpha^{\prime}$-martensitic formation. The twin boundaries effectively acted as nucleation sites for martensitic transformation in the microstructure with lower bimodality factor. The transformation paths were realized to be completely different in both bimodal grain-sized structures; the $\alpha^{\prime}$-martensite was observed at the intersections of deformation twins and $\varepsilon$ martensite platelets in the structures with lower and higher bimodality factors, respectively.

\section{References}

[1] H. Ding, H. Ding, D. Song, Z. Tang, P. Yang, Strain hardening behavior of a TRIP/TWIP steel with $18.8 \%$ Mn, Mater. Sci. Eng. A. 528 (2011) 868-873.

[2] A.S. Hamada, L.P. Karjalainen, M.C. Somani, The influence of aluminum on hot deformation behavior and tensile properties of high-Mn TWIP steels, Mater. Sci. Eng. A. 467 (2007) 114-124.

[3] M. Eskandari, A. Zarei-Hanzaki, J.A. Szpunar, M.A. Mohtadi-Bonab, A.R. Kamali, M. Nazarian-Samani, Microstructure evolution and mechanical behavior of a new microalloyed high Mn austenitic steel during compressive deformation, Mater. Sci. Eng. A. 615 (2014) 424-435.

[4] A. Dumay, J.P. Chateau, S. Allain, S. Migot, O. Bouaziz, Influence of addition elements on the stacking-fault energy and mechanical properties of an austenitic Fe-Mn-C steel, 
Mater. Sci. Eng. A. 483-484 (2008) 184-187.

[5] B.X. Huang, X.D. Wang, Y.H. Rong, L. Wang, L. Jin, Mechanical behavior and martensitic transformation of an Fe-Mn-Si-Al-Nb alloy, Mater. Sci. Eng. A. 438-440 (2006) 306-311.

[6] T.B. Hilditch, T. de Souza, P.D. Hodgson, Properties and automotive applications of advanced high-strength steels (AHSS), Elsevier Ltd, 2015.

[7] G.B. Olson, M. Cohen, Kinetics of strain-induced martensitic nucleation, Metall. Mater. Trans. A. 6 (1975) 791-795.

[8] P. Dastur, A. Zarei-Hanzaki, M.H. Pishbin, M. Moallemi, H.R. Abedi, Transformation and twinning induced plasticity in an advanced high Mn austenitic steel processed by martensite reversion treatment, Mater. Sci. Eng. A. 696 (2017) 511-519.

[9] I. Gutierrez-Urrutia, S. Zaefferer, D. Raabe, The effect of grain size and grain orientation on deformation twinning in a Fe-22wt.\% Mn-0.6wt.\% C TWIP steel, Mater. Sci. Eng. A. 527 (2010) 3552-3560.

[10] M. Linderov, C. Segel, A. Weidner, H. Biermann, A. Vinogradov, Deformation mechanisms in austenitic TRIP/TWIP steels at room and elevated temperature investigated by acoustic emission and scanning electron microscopy, Mater. Sci. Eng. A. 597 (2014) 183-193.

[11] S. Martin, O. Fabrichnaya, D. Rafaja, Prediction of the local deformation mechanisms in metastable austenitic steels from the local concentration of the main alloying elements, Mater. Lett. 159 (2015) 484-488.

[12] M. Eskandari, A. Zarei-Hanzaki, A. Marandi, An investigation into the mechanical behavior of a new transformation-twinning induced plasticity steel, Mater. Des. 39 (2012) 279-284.

[13] H.E. Sabzi, A.Z. Hanzaki, H.R. Abedi, R. Soltani, A. Mateo, J.J. Roa, The effects of bimodal grain size distributions on the work hardening behavior of a TRansformationTWinning induced plasticity steel, Mater. Sci. Eng. A. 678 (2016) 23-32.

[14] M. Okayasu, H. Fukui, Strain-induced martensite formation in austenitic stainless steel, Mater. Sci. Eng. A. 48 (2013) 6157-6166.

[15] L.I. Zhuang, W. Di, Influence of Hot Rolling Conditions on the Mechanical Properties of Hot Rolled TRIP Steel, Journal of Wuhan University of Technology-Mater. Sci. Ed. 23.1 (2008), 74-79.

[16] I. Gutierrez-Urrutia, D. Raabe, Dislocation and twin substructure evolution during strain hardening of an Fe-22 wt.\% Mn-0.6 wt.\% C TWIP steel observed by electron channeling 
contrast imaging, Acta Mater. 59 (2011) 6449-6462.

[17] K.T. Park, Tensile deformation of low-density Fe-Mn-Al-C austenitic steels at ambient temperature, Scr. Mater. 68 (2013) 375-379.

[18] H. Idrissi, K. Renard, L. Ryelandt, D. Schryvers, P.J. Jacques, On the mechanism of twin formation in Fe-Mn-C TWIP steels, Acta Mater. 58 (2010) 2464-2476.

[19] D. Barbier, N. Gey, S. Allain, N. Bozzolo, M. Humbert, Analysis of the tensile behavior of a TWIP steel based on the texture and microstructure evolutions, Mater. Sci. Eng. A. 500 (2009) 196-206.

[20] D.R. Steinmetz, T. Japel, B. Wietbrock, P. Eisenlohr, I. Gutierrez-Urrutia, A. SaeedAkbari, T. Hickel, F. Roters, D. Raabe, Revealing the strain-hardening behavior of twinning-induced plasticity steels: Theory, simulations, experiments, Acta Mater. 61 (2013) 494-510.

[21] H. Xchumann, Zur Kristallographie der martensitischen $\varepsilon \rightarrow \alpha$-Gitterumwandlung, Crystal Research and Technology 11.6 (1976) 663-671.

[22] L. Chen, Y. Zhao, X. Qin, Some aspects of high manganese twinning-induced plasticity (TWIP) steel, a review, Acta Metall. Sin. English Lett. 26 (2013) 1-15.

[23] A.K. De, D.C. Murdock, M.C. Mataya, J.G. Speer, D.K. Matlock, Quantitative measurement of deformation-induced martensite in 304 stainless steel by X-ray diffraction, Scr. Mater. 50 (2004) 1445-1449. 
Table. 1. The characterization of microstructural bimodality in the experimental TRIP-TWIP steel after processing in different conditions.

\begin{tabular}{|l|c|c|}
\hline $\begin{array}{l}\text { Rolling } \\
\text { conditions }\end{array}$ & $1000^{\circ} \mathrm{C}$ & $1200^{\circ} \mathrm{C}$ \\
\hline$D_{f}(\mu \mathrm{m})$ & 8.9 & 7.9 \\
\hline$f_{f}$ & 0.58 & 0.73 \\
\hline$D_{c}(\mu \mathrm{m})$ & 22.8 & 54.6 \\
\hline$f_{c}$ & 0.42 & 0.27 \\
\hline$D_{\text {avg }}(\mu \mathrm{m})$ & 16.2 & 21.9 \\
\hline \multicolumn{2}{|c|}{ Bimodality parameter } \\
\multicolumn{2}{|c|}{} \\
\hline$\Delta D$ & 13.9 & 46.7 \\
\hline$\Delta D / D_{\text {avg }}$ & 0.9 & 2.1 \\
\hline$D_{c} / D_{f}$ & 2.7 & 6.9 \\
\hline
\end{tabular}

$D_{f}$ : Average grain size of fine grain regions $(<15 \mu \mathrm{m}) ; \mathrm{D}_{\mathrm{c}}$ : Average grain size of coarse grain regions; $D_{\text {avg }}$ : Numerical average grain size; $f_{c}$ : Fraction of coarse grain regions; $f_{f}$ : Fraction of fine grain regions; and $\Delta D=D_{c^{-}} D_{f}$. 
(a)

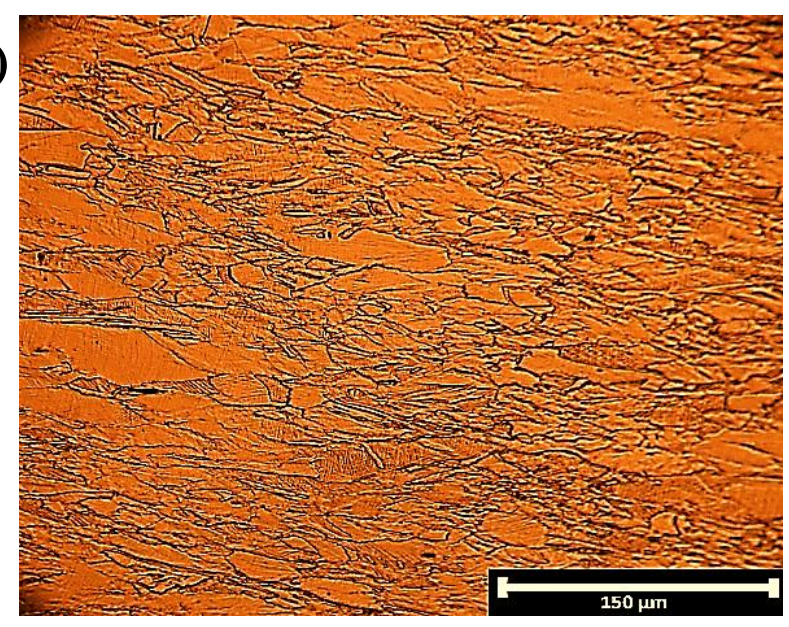

(c)

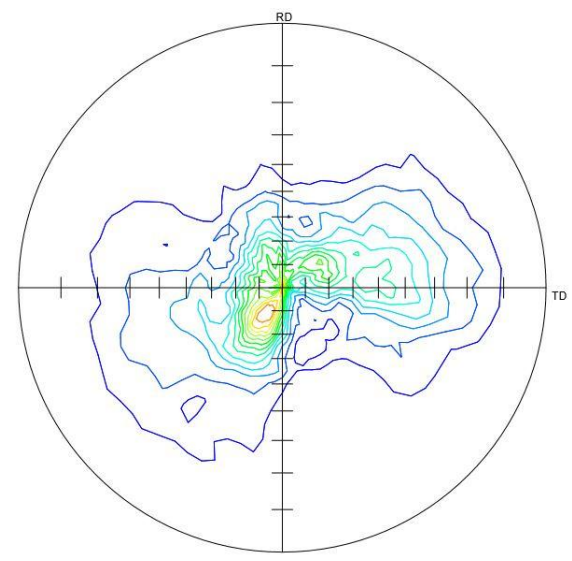

\begin{tabular}{r|c|r|r|l|r|r|r|r|}
\hline No. & Line & Level & No. & Line & Level & No. & Line & Level \\
\hline 1 & 0.565 & 6 & & 3.392 & 11 & & 6.219 \\
\hline 2 & 1.131 & 7 & & 3.957 & 12 & & 6.784 \\
\hline 3 & 1.696 & 8 & & 4.523 & 13 & & 7.350 \\
\hline 4 & & 2.261 & 9 & & 5.088 & 14 & & 7.915 \\
\hline 5 & & 2.827 & 10 & & 5.654 & 15 & & 8.480 \\
\hline
\end{tabular}

(d)

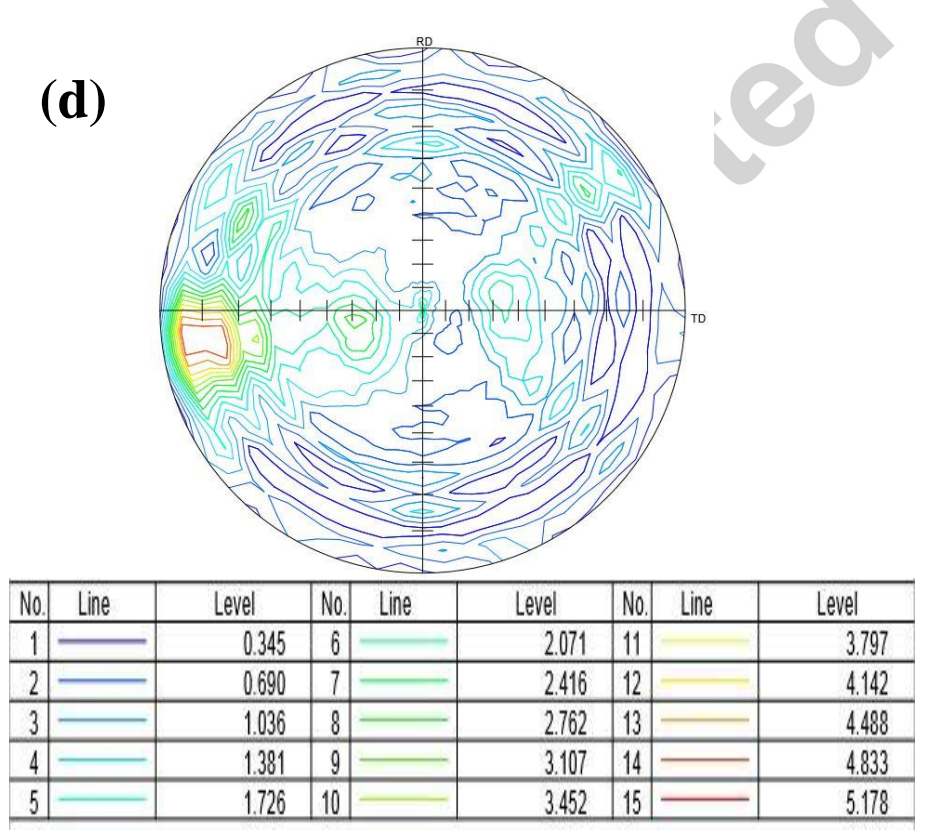

\begin{tabular}{|c|c|r|r|l|r|l|l|r|}
\hline No. & Line & Level & No. Line & Level & No. & Line & Level \\
\hline 1 & & 0.345 & 6 & & 2.071 & 11 & & 3.797 \\
\hline 2 & & 0.690 & 7 & & 2.416 & 12 & & 4.142 \\
\hline 3 & & 1.036 & 8 & & 2.762 & 13 & & 4.488 \\
\hline 4 & & 1.381 & 9 & & 3.107 & 14 & & 4.833 \\
\hline 5 & & 1.726 & 10 & & 3.452 & 15 & & 5.178 \\
\hline
\end{tabular}

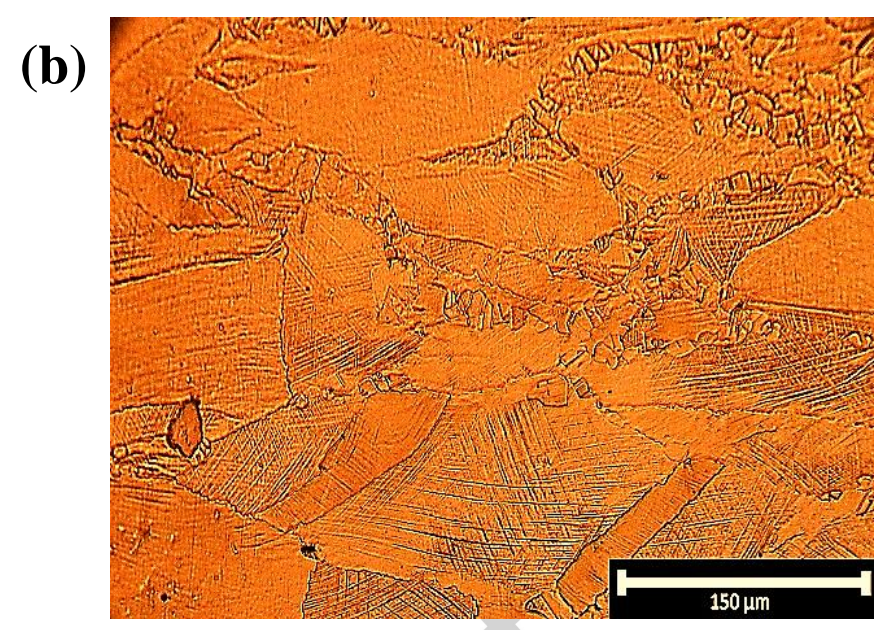

(e)

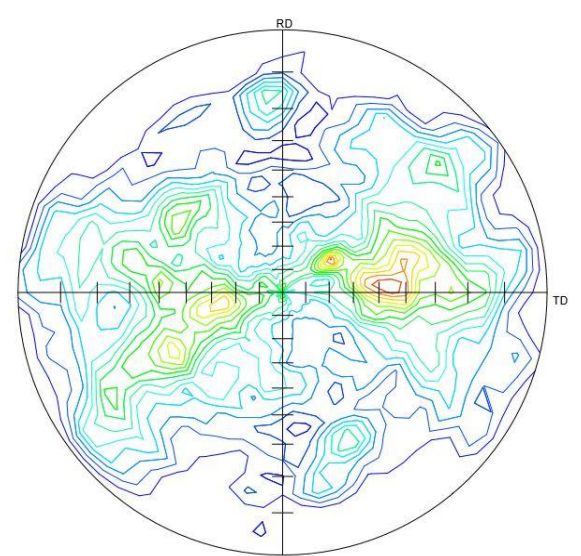

\begin{tabular}{r|c|r|r|l|r|l|l|r}
\hline No. & Line & Level & No. & Line & Level & No. & Line & Level \\
\hline 1 & & 0.236 & 6 & & 1.416 & 11 & & 2.596 \\
\hline 2 & & 0.472 & 7 & & 1.652 & 12 & & 2.832 \\
\hline 3 & & 0.708 & 8 & & 1.808 & 13 & & 3.068 \\
\hline 4 & & 0.944 & 9 & & 2.124 & 14 & & 3.304 \\
\hline 5 & & 1.180 & 10 & & 2.360 & 15 & & 3.540 \\
\hline
\end{tabular}

Fig. 1. Initial microstructure of the specimens after hot rolling at (a) $1000^{\circ} \mathrm{C}$ and (b) $1200^{\circ} \mathrm{C}$, prior to tensile testing, (c) (111) pole figure of the as-received specimen, (d) (111) pole figure of the specimen after hot rolling at $1000^{\circ} \mathrm{C}$ and (e) (111) pole figure of the specimen after hot rolling at $1200^{\circ} \mathrm{C}$. 

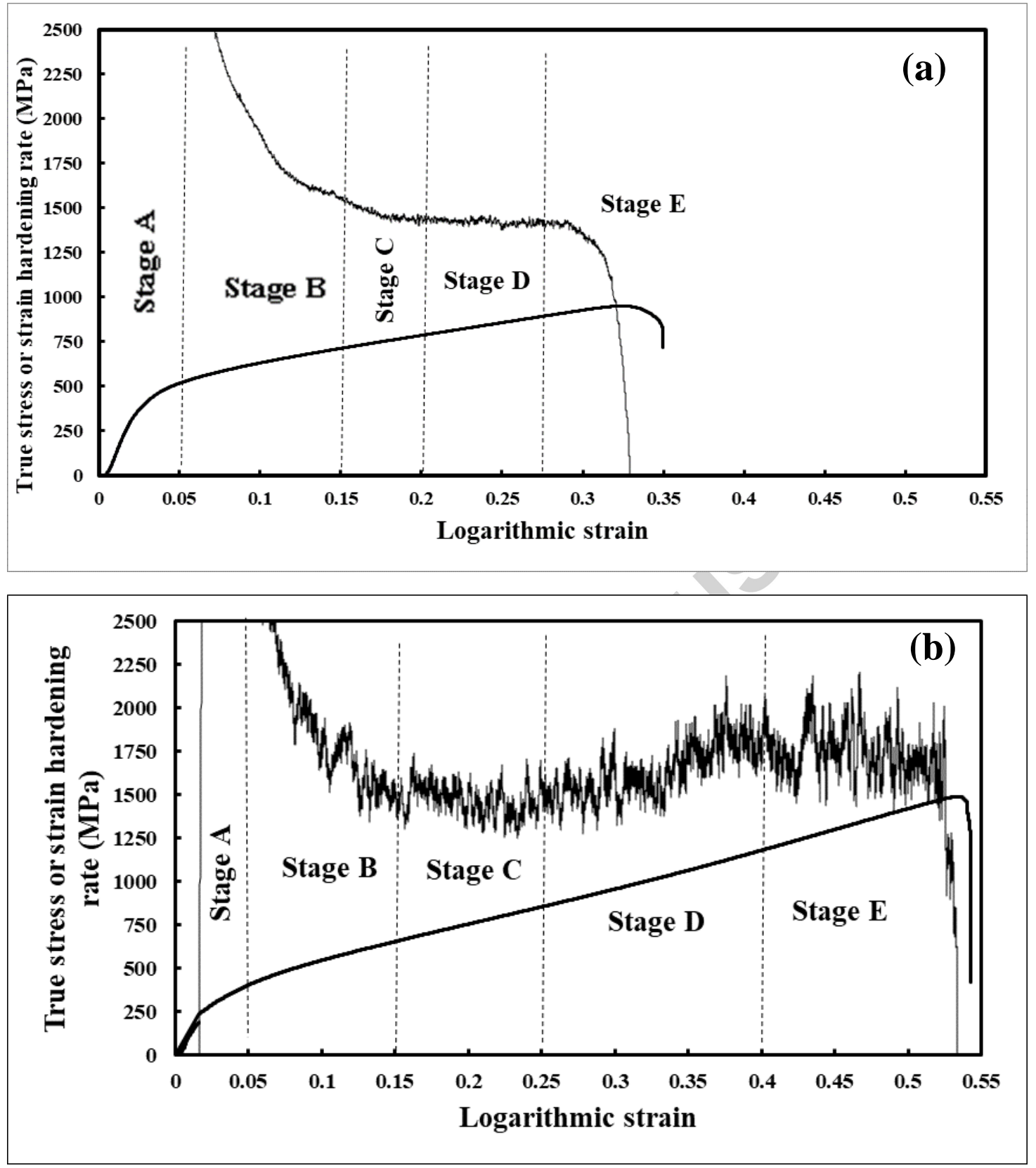

Fig. 2. True stress vs. logarithmic strain behaviors of the experimental steel obtained through tensile testing at ambient temperature after thermomechanical processing at: (a) $1000^{\circ} \mathrm{C}$, and (b) $1200^{\circ} \mathrm{C}$; the corresponding strain hardening curves are also superimposed. 

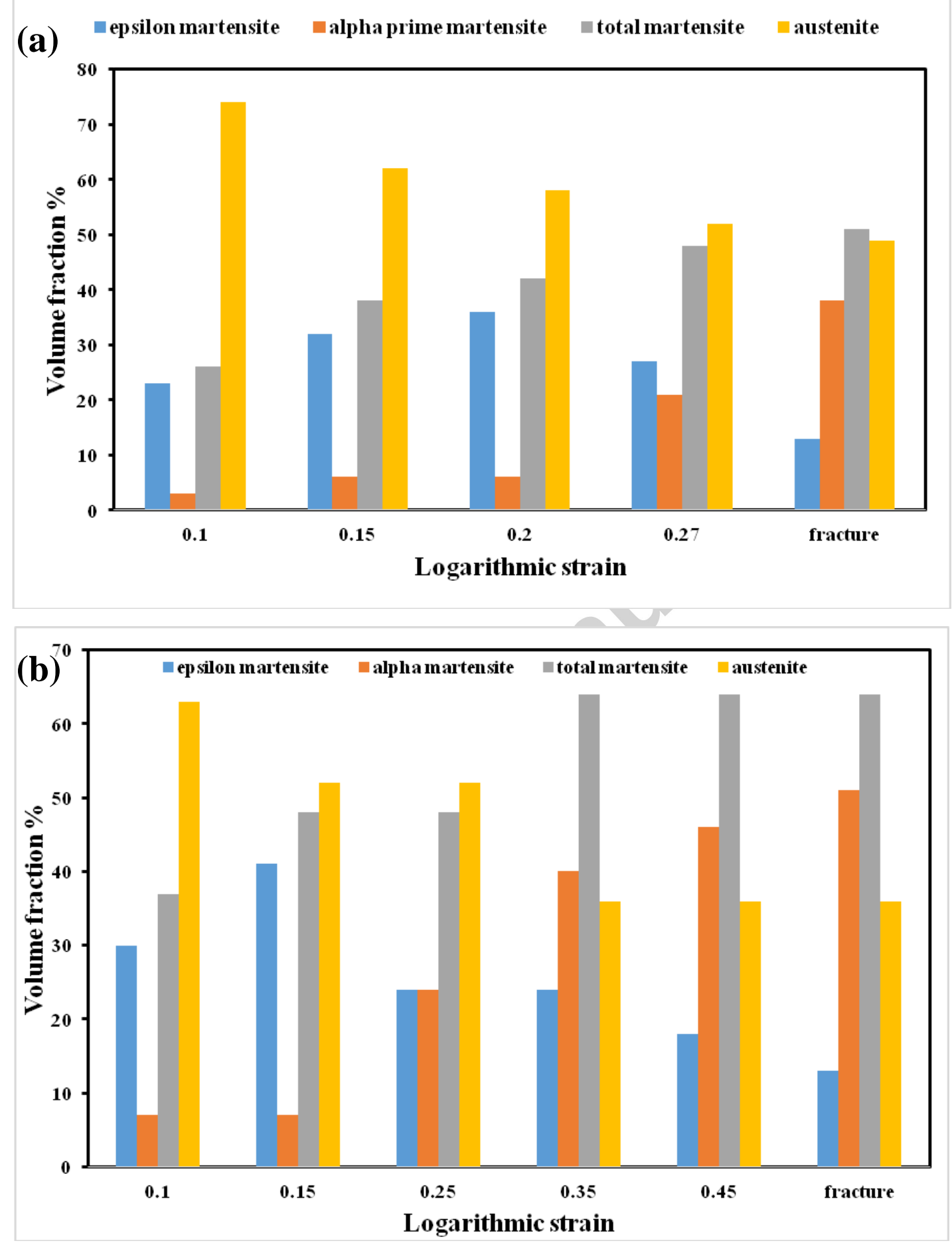

Fig. 3. The variation of micro-constituents volume fractions with logarithmic strain during room temperature tensile straining for experimental material thermomechanically processed at (a) $1000^{\circ} \mathrm{C}$, and (b) $1200^{\circ} \mathrm{C}$. 
(a) - - - epsilon martensite $\quad--$ alpha prime martensite
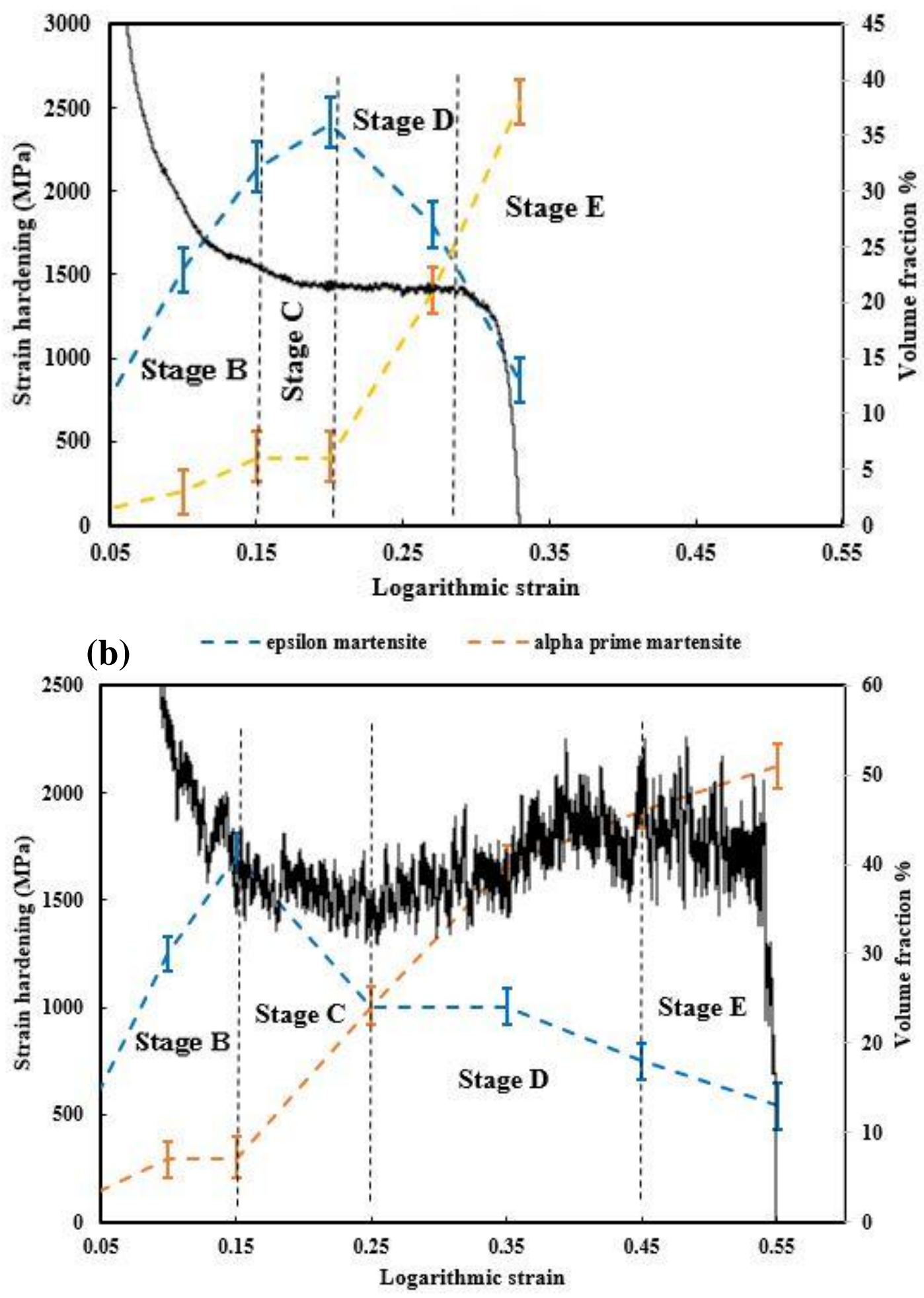

Fig. 4. The martensite volume fraction as a function of logarithmic strain and its correlation with the rate of strain hardening for the experimental material processed at: (a) $1000^{\circ} \mathrm{C}$, and (b) $1200^{\circ} \mathrm{C}$ (the plastic regions are only represented). 

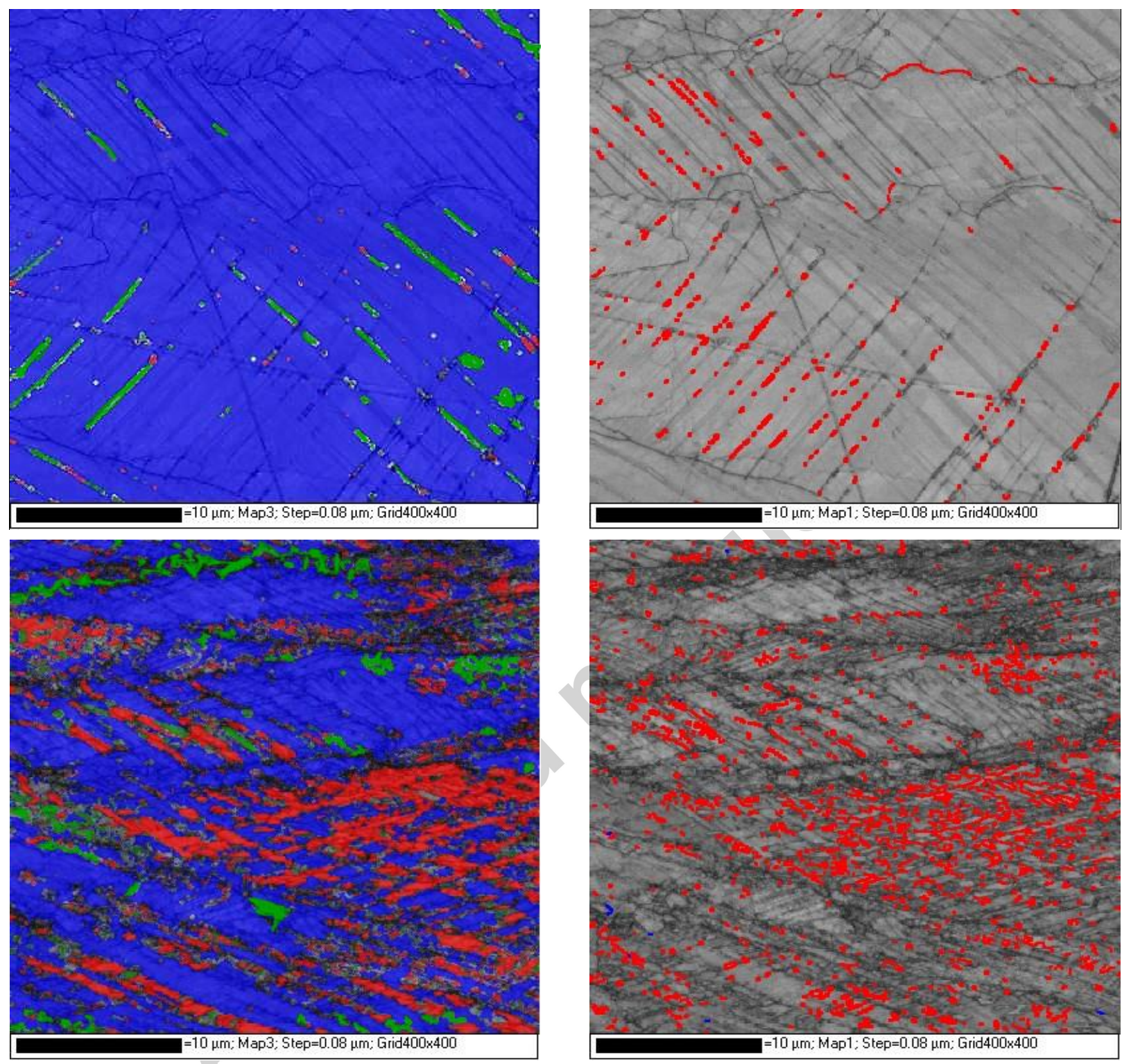

Fig. 5. The phase maps superimposed on image quality maps of tensile deformed microstructures up to the logarithmic strain of (a) 0.1 , and (c) 0.27 . The tensile specimens were machined from the material which had been previously thermomechanically processed at $1000^{\circ} \mathrm{C}$. The blue, green and red areas indicate the presence of austenite, $\varepsilon$-martensite and $\alpha^{\prime}$-martensite, respectively. The corresponding twin boundary maps are also depicted in (b) and (d), respectively. 

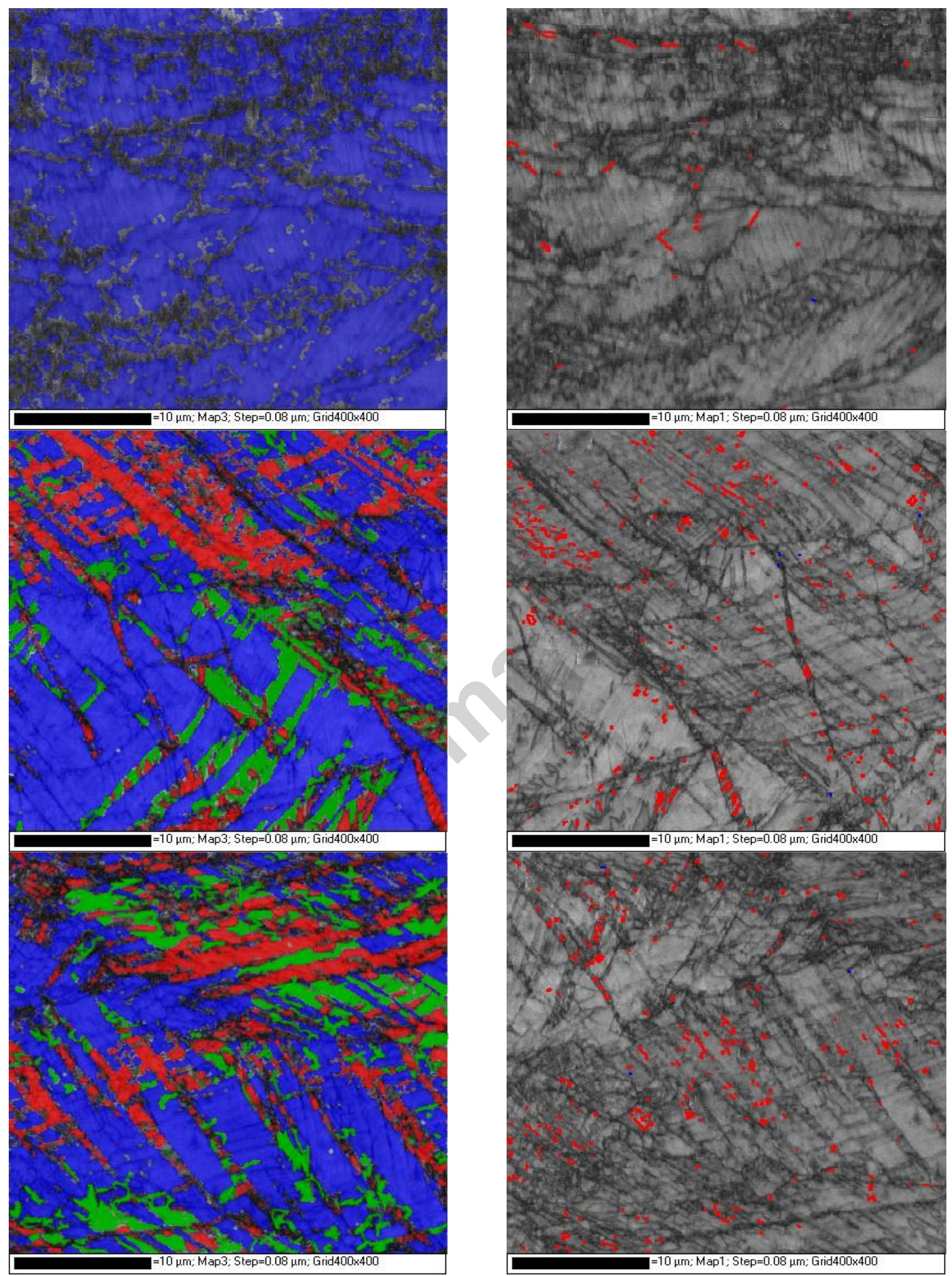

Fig. 6. Phase maps of the processed material at $1200^{\circ} \mathrm{C}$ after tensile deformation up to the logarithmic strain of (a) 0.1 , (c) 0.35 and (e) 0.45 . Austenite is shown in blue, $\varepsilon$-martensite in green and gray and $\alpha^{\prime}$-martensite in red. The corresponding twin boundary maps are given in (b), (d), and (f), respectively. 


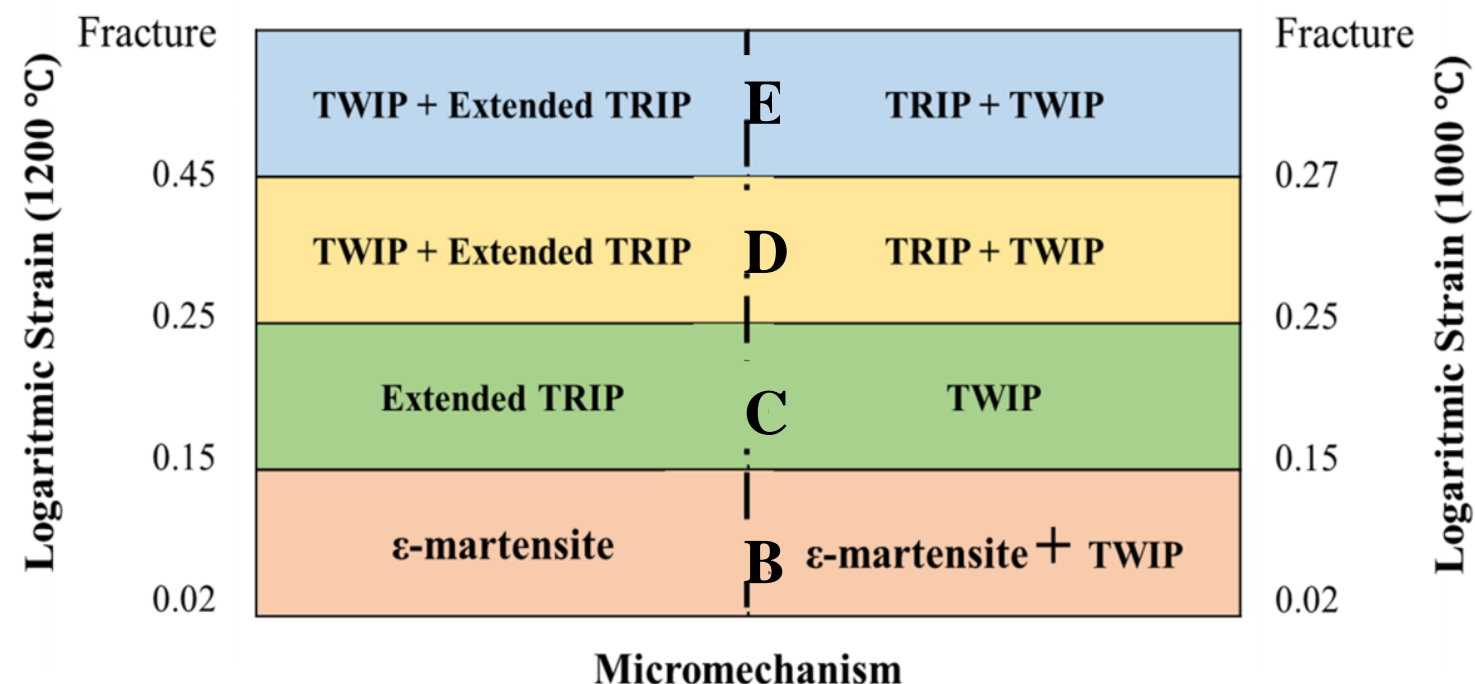

Fig. 7. The schematic representation of deformation sequences and their related micro-mechanism of the materials hot rolled at 1000 and $1200^{\circ} \mathrm{C}$. 